\title{
Role of Mesohepatectomy with or without Transcatheter Arterial Chemoembolization for Large Centrally Located Hepatocellular Carcinoma
}

\author{
Xiao-ping Chen ${ }^{\mathrm{a}}$ Dao-yu Hu ${ }^{\mathrm{b}}$ Zhi-wei Zhang ${ }^{\mathrm{a}}$ Bi-xiang Zhang ${ }^{\mathrm{a}} \quad$ Yi-fa Chen $^{\mathrm{a}}$ \\ Wan-guang Zhang ${ }^{\text {a }}$ Fa-zu Qiu ${ }^{a}$ \\ a Hepatic Surgery Center, and ${ }^{\mathrm{b}}$ Department of Radiology, Tongji Hospital, Tongji Medical College, \\ Huazhong University of Science and Technology, Wuhan, PR China
}

\section{Key Words}

Transcatheter arterial chemoembolization $\cdot$ Hepatocellular carcinoma $\cdot$ Mesohepatectomy $\cdot$ Survival rate

\begin{abstract}
Background: The role of preoperative transcatheter arterial chemoembolization (TACE) for resectable hepatocellular carcinoma (HCC) was controversial. Methods: 246 patients with large centrally located HCC underwent mesohepatectomy $(\mathrm{MH})$ and were divided into two groups: group $\mathrm{A}, 89$ patients with preoperative TACE; group $B, 157$ patients without preoperative TACE. The aim was to evaluate the influence of preoperative TACE on postoperative complications and long-term results of patients with large centrally located HCC. Results: In the 89 patients of the TACE-MH group, a total of 123 (mean 1.4 per patient) preoperative TACEs were performed. The differences in postoperative complications ( 34.8 vs. $24.2 \% ; p=0.075$ ) and overall hospital mortality ( 3.4 vs. $0.6 \% ; p=0.103$ ) between the two groups were not significant. The postoperative recurrence rate in the remnant liver was higher in the MH group than in the TACE-MH group (79.6 vs. $73.0 \%$ ), while the extrahepatic metastasis rate in the TACE-MH group was higher than that in the MH group (11.1 vs. 7.0\%). Overall 1-, 3-, and 5-year survival rates were 87.1, 62.9 , and $46.2 \%$, respectively, for the TACE-MH group, and $82.2,54.4$, and $31.7 \%$, respectively, for the MH group $(p=$
\end{abstract}

$0.001) ; 1-, 3-$, and 5-year disease-free survival rates were 75.0, 46.2 , and $31.8 \%$, respectively, for the TACE-MH group, and $69.6,38.0$, and $16.5 \%$, respectively, for the MH group $(p=$ 0.002). Conclusions: Long-term outcomes of patients with preoperative TACE were improved and the pattern of the recurrences after surgery was altered. The patients with large centrally located HCC could benefit more from this neoadjuvant treatment, although there was some influence of preoperative TACE on postoperative complications.

Copyright $\odot 2007$ S. Karger AG, Basel

Hepatocellular carcinoma (HCC) is one of the commonest malignant diseases in China, with an annual incidence of $24.0 / 100,000$ population [1-4]. So far, liver resection has been considered the first choice and the most effective treatment for HCC. For large centrally located tumors, however, mesohepatectomy (MH) is not recommended or may even be contraindicated, because of the technical complexity of this operation $[5,6]$. Until now, this operation has seldom been performed in western countries $[7,8]$.

Transcatheter arterial chemoembolization (TACE) is another option for the patients with large centrally located HCC. TACE was initially used as a palliative therapeutic procedure for unresectable HCC $[9,10]$ and now, it is frequently performed as a preoperative adjuvant therapy

\section{KARGER}

Fax +4161306 1234 E-Mail karger@karger.ch www.karger.com (c) 2007 S. Karger AG, Basel

0253-4886/07/0243-0208\$23.50/0

Accessible online at:

www.karger.com/dsu
Xiao-Ping Chen, MD, PhD, FACS

Hepatic Surgery Center and Institute of HBP Surgery, Tongji Hospital

Tongji Medical College, Huazhong University of Science and Technology

Wuhan 430030 (PR China)

Tel. +86278366 2599, Fax +86 278366 2851, E-Mail ChenXP@medmail.com.cn 
for resectable HCC in some medical centers [11-15]. According to previous studies, however, preoperative TACE has both possible advantages and disadvantages [16-18].

In this retrospective study, the aims are firstly to evaluate the influence of preoperative TACE on $\mathrm{MH}$ and postoperative complications, and secondly to determine whether patients with large centrally located HCC benefit more from preoperative TACE.

\section{Patients and Methods}

From January 1990 to December 2004, a total of 246 patients whose main tumors were centrally located (defined as tumors confined to Couinaud's segments IV, V, and VIII) underwent $\mathrm{MH}$. Among them, 89 patients had undergone TACE before $\mathrm{MH}$ (TACE-MH group), and 157 patients underwent $\mathrm{MH}$ (MH group) directly after diagnosis. For preoperative TACE, the following two criteria had to be met: (a) based on CT volumetric measurement, the volume of the unaffected liver tissue was less than $60 \%$ of the whole liver, and (b) the liver functions of the patients were graded as Child-Pugh B or C. The criteria for hepatic resection were: (a) the volume of the unaffected liver tissue was more than $60 \%$ of the whole liver, and (b) the liver functions of the patients were graded as Child-Pugh A or B.

A catheter was inserted selectively into the right or left hepatic artery or the tumor-feeding artery if it existed by Seldinger's technique. The anticancer agents used were three combinations of 1,000 mg 5-fluorouracil, $6 \mathrm{mg}$ mitomycin C, and $40 \mathrm{mg}$ cisplatin, and the embolization agents used were Lipiodol $(5-20 \mathrm{ml}$, according to the tumor size) and gelatin sponge. If the average diameter of the main tumor had decreased by at least 30\% (compared with that seen on previous imaging) on the CT scan performed 4-6 weeks later, or if a fall of at least $50 \%$ of plasma $\alpha$ fetoprotein (AFP) levels was observed, a second preoperative TACE was performed 6-8 weeks after the first TACE; this cycle was never repeated more than twice. Resections were performed after a mean delay of $26 \pm 15$ days after the last TACE.

The potential for MH of centrally located HCC was assessed mainly by ultrasonography, CT, magnetic resonance imaging and, sometimes, by angiography. Liver function was assessed by a combination of Child-Pugh classification and liver biochemistry. Our criteria for $\mathrm{MH}$ were: firstly, Child-Pugh classification was $\mathrm{A}$ or $\mathrm{B}$, and secondly, radiological studies showed that compensatory hyperplasia of nonneoplastic liver tissue reached $60 \%$ of the whole liver volume.

\section{Surgical Techniques}

The techniques have been described previously [2, 3, 19]. Briefly, an abdominal incision without thoracotomy was used in all patients. The round ligament and falciform ligament were divided, and the liver was partially mobilized. Intraoperative ultrasonography was routinely performed to accurately determine the number and location of the lesions, their relationship to the right and left portal veins, right and left hepatic veins, and right posterior portal vein, and to rule out other lesions not apparent on preoperative radiologic study.

Mesohepatectomy with or without TACE
All operations were performed by the same surgical team. At first, with traction on the round ligament, vessels to the left medial segment were divided and ligated just to the right of the round and falciform ligaments, and then, transection of the liver parenchyma was performed along the demarcation line between the right anterior and posterior segments using a Kelly forceps and ERBE VIO crushing clamp. Complete hepatic inflow occlusion was used during the period of liver parenchyma transection. In some patients, apart from complete hepatic inflow occlusion, the inferior vena cava below the liver was dissected and taped with a vascular tape during the liver transection. The biliary and vascular radicles, and the middle hepatic vein draining the part of the liver to be resected were ligated and divided intrahepatically. The gallbladder and the tumor-bearing liver were resected en bloc. The liver cut surface at the end of the procedure was sutured and sealed with $5 \mathrm{ml}$ of fibrin sealant (Guangzhou Bioseal Biotech Co. Ltd., China). These approaches were adopted for lowering postoperative bile leakage in our patients. Abdominal drainage was placed routinely.

To assess the antitumoral effect of preoperative TACE, the tumor size and AFP levels were measured prior to and after TACE. In both groups, intraoperative difficulties and operative duration were collected from the detailed operative notes of surgical resections. Postoperative morbidity and mortality were recorded. Long-term follow-up after surgery included serum AFP measurement, ultrasonography every 4-6 weeks, and chest radiography every 8-12 weeks during the first 2 postoperative years and at 12 to 24-week intervals thereafter. CT, magnetic resonance imaging or hepatic angiography was performed when intrahepatic recurrence was suspected.

A microcomputer was used for the storage, analysis and statistical treatment of the clinical data. The cumulative survival rates and the cumulative survival rates without recurrence were calculated using the Kaplan-Meier method. Statistical differences were tested by the log-rank method. Continuous data were analyzed using the Student t test. $\mathrm{p}<0.05$ was considered statistically significant.

\section{Results}

Clinical, surgical and postoperative data for the two groups of patients are shown in tables 1-3. Regarding clinical features, no statistically significant differences were found between the two groups at the time of diagnosis of HCC.

In the 89 patients of the TACE-MH group, a total of 123 preoperative TACEs were performed. Of them, preoperative TACE was performed once in 55 cases and twice in 34 cases. In general, the mean plasma AFP level was not significantly reduced by TACE $(2,838 \pm 1,721 \mathrm{ng} / \mathrm{ml}$ prior to the first TACE vs. $1,965 \pm 1,105 \mathrm{ng} / \mathrm{ml}$ after the last TACE; $p=0.063$ ). Similarly, preoperative TACE did not result in a significant decrease in tumor size $(10.3 \pm 2.2$ $\mathrm{cm}$ prior to the first TACE vs. $9.5 \pm 2.6 \mathrm{~cm} \mathrm{4-6}$ weeks after the last TACE; $\mathrm{p}=0.187$ ), i.e. there were 25 patients 
Table 1. Clinical features of 246 patients with and without preoperative TACE

\begin{tabular}{lccc}
\hline Variables & $\begin{array}{c}\text { TACE-MH } \\
\text { group }(\mathrm{n}=89)\end{array}$ & $\begin{array}{l}\text { MH group } \\
(\mathrm{n}=157)\end{array}$ & $\begin{array}{l}\mathrm{p} \\
\text { value }\end{array}$ \\
\hline Age, years & $45.5 \pm 6.3$ & $48.6 \pm 5.7$ & 0.083 \\
Sex (male/female) & $71 / 18$ & $136 / 21$ & 0.158 \\
HBsAg positive & $75(84.3)$ & $131(83.4)$ & 0.865 \\
Total bilirubin, mg/dl & $0.71 \pm 0.34$ & $0.69 \pm 0.37$ & 0.136 \\
Serum albumin, g/dl & $3.8 \pm 0.44$ & $3.9 \pm 0.51$ & 0.151 \\
Child-Pugh score & & & 0.492 \\
$\quad$ A & $78(87.6)$ & $142(90.4)$ & \\
$\quad$ B & $11(12.4)$ & $15(9.6)$ & \\
Liver cirrhosis & $74(83.1)$ & $132(84.1)$ & \\
$\quad$ Mild & $15(16.9)$ & $25(15.9)$ & \\
$\quad$ Absent & & & 0.849 \\
Esophageal varices & $51(57.3)$ & $94(59.8)$ & \\
$\quad$ Slight & $38(42.7)$ & $63(40.2)$ & \\
$\quad$ Absent & $2,838 \pm 1,721$ & $2,335 \pm 1,088$ & 0.067 \\
Mean AFP level, ng/ml & & & \\
\hline
\end{tabular}

HBsAg = Hepatitis B surface antigen. Figures in parentheses indicate percentages.

in whom tumor size remained unchanged $(10.8 \pm 3.3$ $\mathrm{cm}), 17$ patients in whom tumor size increased $(9.5 \pm 2.7$ $\mathrm{cm}$ prior to the first TACE vs. $12.7 \pm 3.8 \mathrm{~cm}$ after the last TACE; $\mathrm{p}=0.033$ ), and 47 patients in whom the tumor size decreased $(11.8 \pm 3.4 \mathrm{~cm}$ vs. $8.6 \pm 2.7 \mathrm{~cm} ; \mathrm{p}=0.041)$.

Histopathologic examination on resected specimens revealed no significant differences in liver cirrhosis, surgical margin, encapsulation of the tumor, capsule invasion, and vascular invasion between the two groups (table 2). However, tumor necrosis was found to be more frequent and extensive in the TACE-MH group ( $\mathrm{p}=$ 0.023 ), but complete necrosis of the main tumor was found in only 1 case.

The extent of resections, the duration of parenchyma transection and the duration of hepatic inflow occlusion were comparable in the two groups (table 2). In contrast, total time of $\mathrm{MH}$ was significantly longer in the TACE$\mathrm{MH}$ group than in the $\mathrm{MH}$ group $(177 \pm 19$ min vs. 115 $\pm 16 \mathrm{~min} ; \mathrm{p}=0.033$ ). This was related to a more difficult dissection in the TACE-MH group due to perihepatic adhesions, chronic cholecystitis and inflammatory pediculitis (table 2). Overall ischemia time was slightly longer in the TACE-MH group, but there was no statistically significant difference (table 2). Patients in the TACE-MH group had more intraoperative blood loss (790 vs. 420 $\mathrm{ml}$ ), and a greater proportion required intraoperative
Table 2. Surgical and histological data between the two groups

\begin{tabular}{|c|c|c|c|}
\hline Variables & $\begin{array}{l}\text { TACE-MH } \\
\text { group } \\
(\mathrm{n}=89)\end{array}$ & $\begin{array}{l}\text { MH } \\
\text { group } \\
(n=157)\end{array}$ & $\begin{array}{l}\mathrm{p} \\
\text { value }\end{array}$ \\
\hline Extent of hepatic resection & & & 0.547 \\
\hline IV, V, VIII segments & $82(92.1)$ & $141(89.8)$ & \\
\hline I, IV, V, VIII segments & $7(7.9)$ & $16(10.2)$ & \\
\hline Perihepatic adhesions & $61(68.5)$ & $19(12.1)$ & $<0.001$ \\
\hline Chronic cholecystitis & $31(34.8)$ & $6(3.8)$ & $<0.001$ \\
\hline Pediculitis & $47(52.8)$ & $3(1.9)$ & 0.002 \\
\hline Total operative time, $\min$ & $177 \pm 19$ & $115 \pm 16$ & 0.033 \\
\hline $\begin{array}{l}\text { Time of parenchyma } \\
\text { transection, min }\end{array}$ & $21 \pm 4.4$ & $16 \pm 2.7$ & 0.063 \\
\hline Intraoperative blood loss, $\mathrm{ml}$ & $790 \pm 430$ & $420 \pm 250$ & 0.057 \\
\hline $\begin{array}{l}\text { Required blood transfusion } \\
\text { during operation }\end{array}$ & $40(44.9)$ & $39(24.8)$ & 0.041 \\
\hline $\begin{array}{c}\text { Total occlusion time of } \\
\text { hepatic inflow, min }\end{array}$ & $15.2 \pm 3.1$ & $11.3 \pm 2.9$ & 0.037 \\
\hline Surgical margin & & & 0.614 \\
\hline$>10 \mathrm{~mm}$ & $17(19.1)$ & $26(16.6)$ & \\
\hline$\leq 10 \mathrm{~mm}$ & $72(80.9)$ & $131(83.4)$ & \\
\hline Number of tumors & & & 0.521 \\
\hline Solitary & $77(86.5)$ & $131(83.4)$ & \\
\hline Multiple & $12(13.5)$ & $26(16.6)$ & \\
\hline Mean tumor size, $\mathrm{cm}$ & $9.5 \pm 2.6$ & $9.9 \pm 3.1$ & 0.055 \\
\hline Encapsulated tumor & $54(60.7)$ & $88(56.1)$ & 0.481 \\
\hline Invasion of the capsule & $21(23.6)$ & $45(28.7)$ & 0.389 \\
\hline Vascular invasion & & & 0.730 \\
\hline Present & $40(44.9)$ & $67(42.7)$ & \\
\hline Absent & $49(55.1)$ & $90(57.3)$ & \\
\hline Tumor necrosis & & & 0.023 \\
\hline None & $29(32.6)$ & $75(47.8)$ & \\
\hline$<50 \%$ & $42(47.2)$ & $81(51.6)$ & \\
\hline$>50 \%$ & $17(19.1)$ & $1(0.6)$ & \\
\hline Complete & $1(1.1)$ & $0(0)$ & \\
\hline
\end{tabular}

Figures in parentheses indicate percentages.

blood transfusion ( 44.9 vs. $24.8 \%$ ), when compared with the patients in the $\mathrm{MH}$ group. There were no intraoperative deaths and complications related with the surgical technique. Overall hospital mortality was $3.4 \%$ for the TACE-MH group, and $0.6 \%$ for the $\mathrm{MH}$ group, without a significant difference $(p=0.103)$. Postoperative complications were more frequent in patients of the TACE-MH group than in those of the $\mathrm{MH}$ group (34.8 vs. $24.2 \%$ ), although there was no significant difference $(\mathrm{p}=0.075)$. No patient in either group required reoperation for postoperative complication.

More patients with postoperative recurrence were noted in the MH group than in the TACE-MH group (86.6 vs. $79.7 \%$ ); however, the difference was not significant 


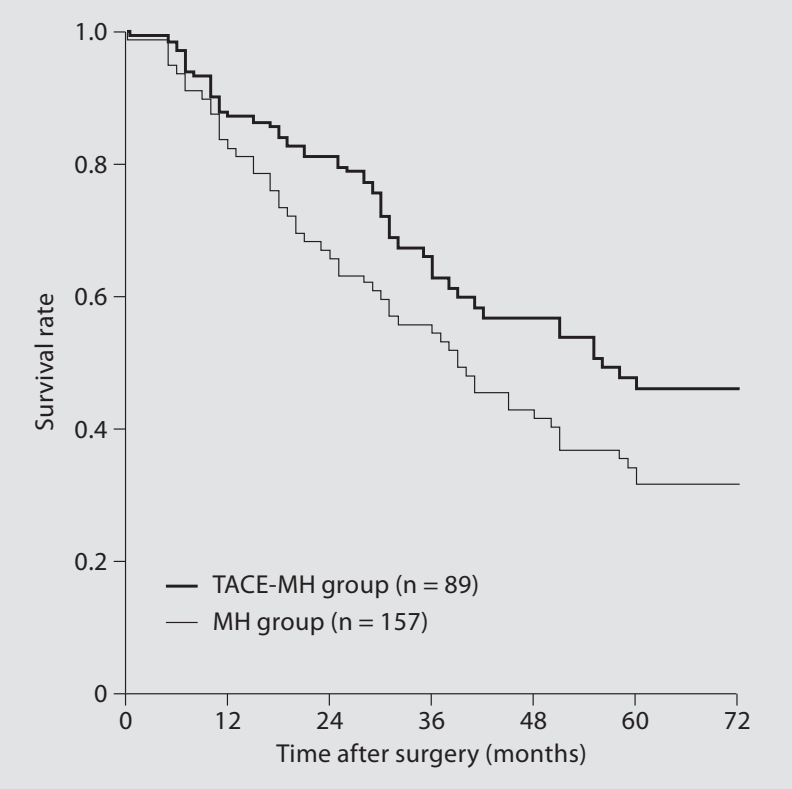

Fig. 1. Overal survival curves after $\mathrm{MH}$ with or without TACE for large centrally located HCC.

Table 3. Postoperative data between the two groups

\begin{tabular}{|c|c|c|c|}
\hline Variables & $\begin{array}{l}\text { TACE-MH } \\
\text { group } \\
(\mathrm{n}=89)\end{array}$ & $\begin{array}{l}\text { MH } \\
\text { group } \\
(n=157)\end{array}$ & $\begin{array}{l}\mathrm{p} \\
\text { value }\end{array}$ \\
\hline Postoperative complication & $31(34.8)$ & $38(24.2)$ & 0.075 \\
\hline Pleural effusion & 11 & 27 & \\
\hline Ascites & 4 & 3 & \\
\hline Stress ulcer bleeding & 0 & 1 & \\
\hline Prolonged jaundice & 2 & 1 & \\
\hline Bile leakage & 1 & 1 & \\
\hline Temporary renal insufficiency & 3 & 1 & \\
\hline Transient encephalopathy & 2 & 1 & \\
\hline Pneumonia & 5 & 2 & \\
\hline Intra-abdominal abscess & 2 & 0 & \\
\hline Wound infection & 1 & 1 & \\
\hline In-hospital mortality & $3(3.4)$ & $1(0.6)$ & 0.103 \\
\hline Liver failure & 2 & 1 & \\
\hline Sepsis & 1 & 0 & \\
\hline Postoperative recurrence & $71(79.7)$ & $136(86.6)$ & 0.158 \\
\hline Extrahepatic metastasis & $6(11.1)$ & $11(7.0)$ & 0.937 \\
\hline Lung metastasis & $4(66.6)$ & $5(45.5)$ & \\
\hline Others & $2(33.4)$ & $6(54.5)$ & \\
\hline Intrahepatic recurrence & $65(73.0)$ & $125(79.6)$ & 0.237 \\
\hline Solitary & $29(44.6)$ & $27(21.6)$ & \\
\hline Multiple & $36(55.4)$ & $98(78.4)$ & \\
\hline Time until recurrence, months & $20 \pm 17$ & $16 \pm 15$ & 0.047 \\
\hline
\end{tabular}

Figures in parentheses indicate percentages.

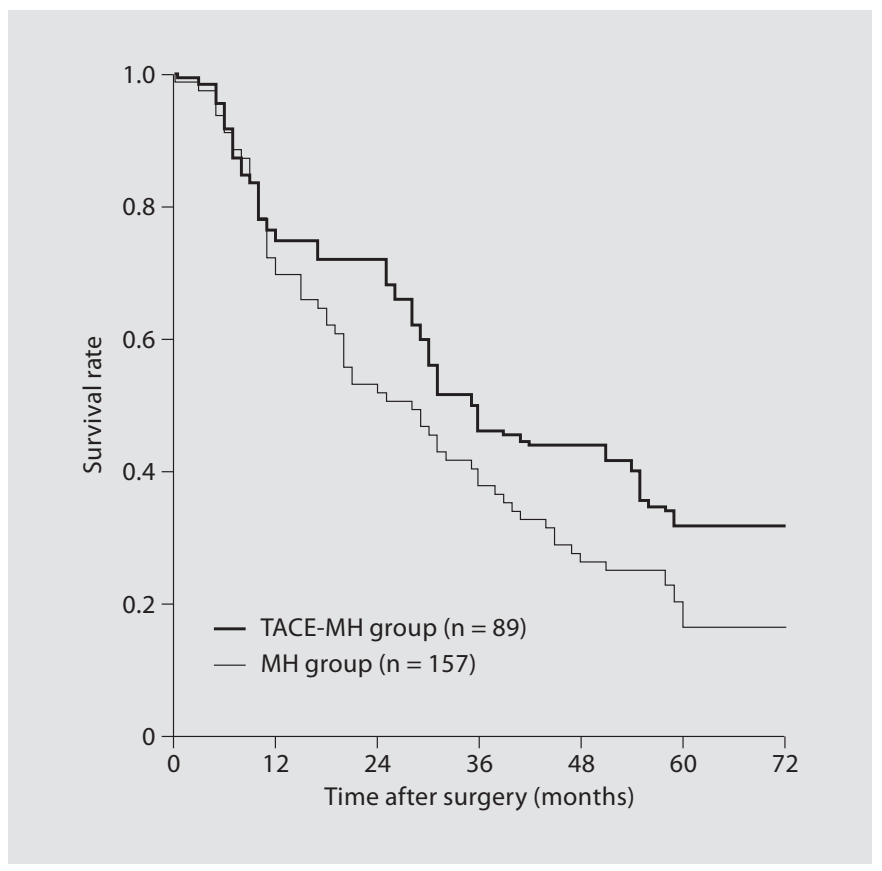

Fig. 2. Disease-free survival curves after $\mathrm{MH}$ with or without TACE for large centrally located HCC.

$(\mathrm{p}=0.158)$. When we compared the pattern of the recurrence (table 3), it was found that the recurrence rate in the remnant liver was higher in the $\mathrm{MH}$ group than in the TACE-MH group (79.6 vs. $73.0 \%$ ), while the extrahepatic metastasis rate in the TACE-MH group was higher than that in the MH group (11.1 vs. 7.0\%). In extrahepatic metastases, however, the lung metastasis rate was higher in the TACE-MH group than in the MH group (66.6 vs. $45.5 \%$ ), and in intrahepatic metastases, the rate of multiple metastases in the MH group was higher than that in the TACE-MH group (78.4 vs. 55.4\%). The mean postoperative period until HCC recurrence was significantly longer in the TACE-MH group than in the MH group (20 vs. 16 months, $\mathrm{p}=0.047$ ).

Overall survival results were significantly better in the TACE-MH group than in the MH group $(\mathrm{p}=0.043$; fig. 1). Cumulative 1-, 3-, and 5-year overall survival rates were $87.1,62.9$, and $46.2 \%$, respectively, for the TACE$\mathrm{MH}$ group, and 82.2, 54.4, and $31.7 \%$, respectively, for the $\mathrm{MH}$ group. Disease-free survival, excluding hospital mortality, was also greater in the TACE-MH group than in the $\mathrm{MH}$ group (fig. 2) ( $\mathrm{p}=0.028)$. Cumulative 1-, 3-, and 5 -year disease-free survival rates were 75.0, 46.2, and $31.8 \%$, respectively, for the TACE-MH group, and 69.6, 38.0 , and $16.5 \%$, respectively, for the $\mathrm{MH}$ group. 


\section{Discussion}

The main purposes of preoperative TACE for resectable HCC are: (1) to improve the detection rate of the other lesions not apparent on pre-TACE radiologic study; (2) to convert initially unresectable tumors to resectable ones, i.e., to induce regression of a huge tumor, enabling safer resection, and (3) to improve long-term results of surgery [11-15]. However, the efficacy of preoperative TACE for resectable HCC is still controversial. Some previous studies have denied the effectiveness of preoperative TACE [20-23], because it was found that preoperative TACE delayed surgery and increased the difficulty during the operation, due to perihepatic dense adhesion, chronic cholecystitis and pediculitis $[16,23,24]$. The others found that there was no significant unfavorable effect coming from the use of preoperative TACE in respect of operating time, blood loss, or mortality $[17,18]$. When compared with the $\mathrm{MH}$ group in the present study, the number of patients in the TACE-MH group with perihepatic adhesions, chronic cholecystitis or thickening of the hepatoduodenal ligament increased, and total operative time was longer, the rate of postoperative morbidity was higher, as was intraoperative blood loss and there was a higher proportion of patients who required blood transfusion during surgery; however, these differences were not significant. These results may be related to the use of the superselectively catheterized technique and the principle of no more than two preoperative TACEs for resectable HCC.

Regarding the pathologic changes after TACE, tumor necrosis has frequently been described. In our study, the tumor necrosis rate in the TACE-MH group was significantly increased. The role of tumor necrosis on prognosis, however, remains controversial. Some authors found that the disease-free survival rates in patients with incomplete tumor necrosis were lower than in those with complete necrosis or without necrosis after preoperative TACE and were even lower than in those without preoperative TACE [24]. It was speculated that in the case of partial necrosis the remaining viable tumor cells are less firmly attached and thus are more likely to become dislodged into the bloodstream during surgical manipulation [25]. Yet a randomized trial on the preventive effect of preoperative TACE on recurrence of HCC has proved that the extent of tumor necrosis did not correlate with the tumor-free survival [26]. In other pathologic changes attributable to preoperative TACE, Higuchi et al. [26] demonstrated that preoperative TACE did not promote encapsulation of the resected HCC or the enlargement of the resection margins [18], both considered favorable prognostic factors [27-30]. For the above reasons, we share the opinion of Sugo et al. [18] that preoperative TACE for patients with resectable HCC should not be performed frequently to achieve complete tumor necrosis because frequent TACE provided no benefits and was associated with disadvantages during surgery.

In regard to long-term outcomes, Uchida et al. [31] reported that the 5 -year survival was lower for patients with preoperative TACE than for those without -24 versus $63 \%$, respectively - ascribing it to progressively deteriorating liver function in patients with cirrhosis owing to preoperative TACE. A prospective randomized trial showed no significant differences in either tumor-free survival or overall survival between patients with or without preoperative TACE $[16,32]$. However, these studies were conducted on patients with resectable tumors, usually less than $5 \mathrm{~cm}$ in diameter $[21,25]$. In our study, however, improvement in long-term outcomes of patients with preoperative TACE was noted when compared with the patients without preoperative TACE. Similar results have been reported in the literature. Yu et al. [24] reported that an appreciable increase in the 3-year survival rate has been obtained in a series of selected patients with huge liver cancers who underwent liver resection after TACE. Lu et al. [17] revealed that preoperative TACE improved both disease-free survival and cumulative survival in patients with tumors $>8 \mathrm{~cm}$ in diameter, but not in patients with a tumor size ranging between $2-8 \mathrm{~cm}$ in diameter.

Sakurai et al. [33] found that preoperative TACE was a prognostic factor related to recurrence after liver resection for HCC. The mechanism would be that embolization leads to immediate necrosis of the tumor and that the secondary granulation along the tumor boundary produces a collapse of the intracapsular veins, tumor emboli, and hence capsular invasion. Okano et al. [34] suggested that preoperative TACE could reduce the rate of diffuse intrahepatic recurrence after liver resection for HCC, because preoperative TACE reduced spillage of viable tumor cells during resection, especially in advancedstage HCC with a high incidence of capsular invasion, vessel involvement, or both. Similar results have been observed in the present study. More patients without preoperative TACE than those with preoperative TACE had postoperative recurrence, although this difference was not significant. Regarding the pattern of recurrence, it was found that the multiple recurrence rate in the remnant liver was higher in the $\mathrm{MH}$ group than in the TACE$\mathrm{MH}$ group, while the rate of extrahepatic metastases, especially lung metastases, in the TACE-MH group was higher than that in the $\mathrm{MH}$ group. 
In conclusion, preoperative TACE for large centrally located HCC could improve the cumulative survival and disease-free survival, or alter the pattern of the recurrences after surgery. There was some influence of preoperative TACE on $\mathrm{MH}$ and postoperative complications, which, however, was not significant.

\section{Acknowledgments}

The authors thank Prof. W.Y. Lau, Department of Surgery, Chinese University of Hong Kong, for reading the manuscript and providing valuable advice, and Dr. S.F. Wang, Shenzhen Central Hospital, Beijing University, for his statistical assistance. This study was partially supported by funds [No. 321 (2001)] from the Chinese Ministry of Public Health for the key clinical projects.

\section{References}

1 Lau WY: Management of hepatocellular carcinoma. J R Coll Surg Edinb 2002;47:389399.

$\checkmark 2$ Chen XP, Qiu FZ, Wu ZD, Zhang BX: Chinese experience with hepatectomy for huge hepatocellular carcinoma. Br J Surg 2004;91: 322-326.

$\checkmark 3$ Chen XP, Huang ZY: Surgical treatment of hepatocellular carcinoma in China: surgical techniques, indications and outcomes. Langenbecks Arch Surg 2005;390:259-265.

$\checkmark 4$ Chen XP, Qiu FZ, Wu ZD, Zhang ZW, Huang ZY, Chen YF: Long-term outcome of resection of large hepatocellular carcinoma. Br J Surg 2006;93:600-606.

$\checkmark 5$ Lin TY, Lee CS, Chen KM: Role of surgery in the treatment of primary carcinoma of the liver: a 31-year experience. Br J Surg 1987;74: 838-842.

-6 McBride LM, Wallance S: Cancer of the right lobe of the liver. Arch Surg 1972;105:289296.

$\checkmark 7$ Scudamore CH, Buczkowski AK, Shayan H: Mesohepatectomy. Am J Surg 2000;179:356360

8 Jacobs M, Mcdonough J, Remine SG: Resection of central hepatic malignant lesions. Am Surg 2003;3:186-190.

$\checkmark 9$ Yamada R, Sato M, Kawabata M, Nakatsuka H, Nakamura K, Takashima S: Hepatic artery embolization in 120 patients with unresectable hepatoma. Radiology 1983;148: 397-401.

-10 Gerunda EG, Neri D, Merenda R, Barbazza F, Zangrandi F, Meduri F, et al: Role of transarterial chemoembolization before liver resection for hepatocarcinoma. Liver Transpl 2000;6:619-626.

-11 Portolani N, Tiberio AM, Bonardelli S, Grazioli L, Matricardi L, Benetti A, et al: Arterial chemoembolization in hepatocellular carcinoma suitable for resective surgery. Hepatogastroenterology 1996;43:1566-1574.

-12 Sitzmann JV: Conversion of unresectable to resectable liver cancer: an approach and follow-up study. World J Surg 1995;19:790-794.

-13 Bismuth H, Morino M, Sherlock D, Castaing D, Miglietta C, Cauquil P, et al: Primary treatment of hepatocellular carcinoma by arterial chemoembolization. Am J Surg 1992; 163:387-394.

- 14 Fujio N, Sakai K, Kinoshita H, Hirohashi K, Kubo S, Iwasa R, et al: Results of treatment of patients with hepatocellular carcinoma with severe cirrhosis of the liver. World J Surg 25 Adachi E, Matsumata T, Nishizaki T, Hashi$1989 ; 13: 211-217$.

15 Imaoka S, Sasaki Y, Shibata T, Fujita M, Kasugai H, Kojima J, et al: A pre-operative chemoembolization therapy using lipiodol, cisplatin and gelatin sponge for hepatocellular carcinoma. Cancer Chemother Pharmacol 1989;23(suppl):S126-S128.

16 Paye F, Jagot P, Vilgrain V, Farges O, Boeie D, Belghiti J: Preoperative chemoembolization of hepatocellular carcinoma: a comparative study. Arch Surg 1998;133:767-772.

17 Lu CD, Peng SY, Jiang XC, Chiba Y, Tanigawa $\mathrm{N}$ : Preoperative transcatheter arterial chemoembolization and prognosis of patients with hepatocellular carcinomas: retrospective analysis of 120 cases. World J Surg 1999;23:293-300.

18 Sugo H, Futagawa SJ, Beppu T, Fukasawa M, Kojima K: Role of preoperative transcatheter arterial chemoembolization for resectable hepatocellular carcinoma: relation between postoperative course and the pattern of tumor recurrence. World J Surg 2003;27:1295-1299.

19 Chen XP: Hepatic Resection. Wuhan, Hubei Science and Technology, 1992, pp 115-123.

20 Hwang TL, Chen MF, Lee TY, Chen TJ, Lin DY, Liaw YF: Resection of hepatocellular carcinoma after transcatheter arterial embolization: re-evaluation of the advantages and disadvantages of preoperative embolization. Arch Surg 1987;122:756-759.

21 Yamasaki S, Hasegawa H, Kinoshita H, Furukawa $\mathrm{M}$, Imaoka S, Takasaki $\mathrm{K}$, et al: A prospective randomized trial of the preventive effect of pre-operative transcatheter arterial embolization against recurrence of hepatocellular carcinoma. Jpn J Cancer Res 1996;87:206-211.

22 Wu CC, Ho YZ, Ho WL, Wu TC, Liu TJ, Peng FK: Preoperative transcatheter arterial chemoembolization for resectable large hepatocellular carcinoma: a reappraisal. Br J Surg 1995;82:122-126.

23 Hanazaki K, Kajikawa S, Shimozawa N, Mihara M, Shimada K, Hiraguri M, et al: Survival and recurrence after hepatic resection of 386 consecutive patients with hepatocellular carcinoma. J Am Coll Surg 2000;191: 381-388.

24 Yu YQ, Xu DB, Zhou XD, Lu JZ, Tang ZY, Mack P: Experience with liver resection after hepatic arterial chemoembolization for hepatocellular carcinoma. Cancer 1993;71:62-65. moto H, Tsuneyoshi M, Sugimachi K: Effects of preoperative transcatheter hepatic arterial chemoembolization for hepatocellular carcinoma: the relationship between postoperative course and tumor necrosis. Cancer 1993;72:3593-3598.

-26 Higuchi T, Kikuchi M, Okazaki M: Hepatocellular carcinoma after transcatheter hepatic arterial embolization: a histopathologic study of 84 resected cases. Cancer 1994;73: 2259-2267.

27 Jwo SC, Chiu JH, Chau GY, Loong CC, Lui WY: Risk factors linked to tumor recurrence of human hepatocellular carcinoma after hepatic resection. Hepatology 1992;16:13671371.

28 Ng IO, Lai EC, Ng MM, Fan ST: Tumor encapsulation in hepatocellular carcinoma: a pathologic study of 189 cases. Cancer 1992; 70:45-49.

29 Yoshida Y, Kanematsu T, Matsumata T, Takenaka K, Sugimachi K: Surgical margin and recurrence after resection of hepatocellular carcinoma in patients with cirrhosis. Ann Surg 1989;209:297-301.

30 Matsumata T, Kanematsu T, Takenaka K, Sugimachi K: Lack of intra-hepatic recurrence of hepatocellular carcinoma by temporary portal venous embolisation with starch microspheres. Surgery 1989;105:188-191.

-31 Uchida M, Kohno H, Kubota H, Hayashi T, Yamanoi A, Kimoto T, et al: Role of preoperative transcatheter arterial oily chemoembolization for resectable hepatocellular carcinoma. World J Surg 1996;20:326-331.

32 Yamasaki S, Hasegawa H, Kinoshita H, Furukawa $M$, Imaoka $S$, Takasaki $K$, et al: $A$ prospective randomized trial of the preventive effect of pre-operative transcatheter arterial embolization against recurrence of hepatocellular carcinoma. Jpn J Cancer Res 1996;87:206-211.

33 Sakurai M, Okamura J, Kuroda C: Transcatheter chemoembolization effective for treating hepatocellular carcinoma. Cancer 1984;54:387-392.

34 Okano A, Hajiro K, Takakura H: Diffuse intrahepatic recurrence after resection of hepatocellular carcinoma. Hepatogastroenterology 2000;47:1356-1359. 